\title{
Malignant Solitary Fibrous Tumor
}

National Cancer Institute

\section{Source}

National Cancer Institute. Malignant Solitary Fibrous Tumor. NCI Thesaurus. Code C6894.

A malignant neoplasm of probable fibroblastic derivation. It is characterized by the presence of atypical round to spindle-shaped cells, increased cellularity, necrotic change and high mitotic activity. 